\title{
Amniotic Mesenchymal Stem Cells: A New Source for Hepatocyte-Like Cells and Induction of CFTR Expression by Coculture with Cystic Fibrosis Airway Epithelial Cells
}

\author{
Valentina Paracchini, ${ }^{1}$ Annalucia Carbone, ${ }^{1,2}$ Federico Colombo, ${ }^{3}$ Stefano Castellani, ${ }^{2}$ \\ Silvia Mazzucchelli, ${ }^{3}$ Sante Di Gioia, ${ }^{2}$ Dario Degiorgio, ${ }^{4}$ Manuela Seia, ${ }^{1}$ Laura Porretti, ${ }^{3}$ \\ Carla Colombo, ${ }^{4}$ and Massimo Conese ${ }^{2}$ \\ ${ }^{1}$ Medical Genetics Laboratory, Fondazione IRCCS Ca' Granda Ospedale Maggiore Policlinico, Via Commenda 12, \\ 20122 Milan, Italy \\ ${ }^{2}$ Department of Biomedical Sciences, University of Foggia, c/o Ospedali Riuniti, Viale L. Pinto 1, 71122 Foggia, Italy \\ ${ }^{3}$ Interdepartmental Center of Cytometry and Experimental Hepatology Laboratory, Fondazione IRCCS Ca' Granda \\ Ospedale Maggiore Policlinico, Via F. Sforza 35, 20122 Milan, Italy \\ ${ }^{4}$ Cystic Fibrosis Center, Fondazione IRCCS Ca' Granda Ospedale Maggiore Policlinico, Via Commenda 9, 20122 Milan, Italy \\ Correspondence should be addressed to Massimo Conese, m.conese@unifg.it
}

Received 15 June 2011; Revised 13 October 2011; Accepted 14 October 2011

Academic Editor: Ken-ichi Isobe

Copyright () 2012 Valentina Paracchini et al. This is an open access article distributed under the Creative Commons Attribution License, which permits unrestricted use, distribution, and reproduction in any medium, provided the original work is properly cited.

Cystic fibrosis (CF) is a monogenic disease caused by mutations in the CF transmembrane conductance regulator (CFTR) gene, with lung and liver manifestations. Because of pitfalls of gene therapy, novel approaches for reconstitution of the airway epithelium and CFTR expression should be explored. In the present study, human amniotic mesenchymal stem cells (hAMSCs) were isolated from term placentas and characterized for expression of phenotypic and pluripotency markers, and for differentiation potential towards mesoderm (osteogenic and adipogenic) lineages. Moreover, hAMSCs were induced to differentiate into hepatocyte-like cells, as demonstrated by mixed function oxidase activity and expression of albumin, alpha1-antitrypsin, and CK19. We also investigated the CFTR expression in hAMSCs upon isolation and in coculture with CF airway epithelial cells. Freshly isolated hAMSCs displayed low levels of CFTR mRNA, which even decreased with culture passages. Following staining with the vital dye CM-DiI, hAMSCs were mixed with CFBE41o- respiratory epithelial cells and seeded onto permeable filters. Flow cytometry demonstrated that 33-50\% of hAMSCs acquired a detectable CFTR expression on the apical membrane, a result confirmed by confocal microscopy. Our data show that amniotic MSCs have the potential to differentiate into epithelial cells of organs relevant in CF pathogenesis and may contribute to partial correction of the CF phenotype.

\section{Introduction}

Human placenta may represent a fruitful reserve of stem cells for regenerative medicine. Amniotic epithelial cells (hAECs) and amniotic mesenchymal stromal cells (hAMSCs) are known to have unique characteristics, such as derivation from early embryological development, low level expression of major histocompatibility complex antigens, and a lessrestricted differentiation potential [1]. In culture, hAECs and hAMSCs can differentiate toward "classic" mesodermal lineages (osteogenic, chondrogenic, and adipogenic), as well as toward cell types of all three germ layers-ectoderm, mesoderm, and endoderm (reviewed in [2,3]). Because the amniotic membrane is discarded after delivery, it is easy to obtain without harming mothers or babies and would thereby overcome the ethical issues associated with the use of embryonic stem cells. Based on these considerations, human amniotic membrane/amnion-derived cells are considered to be a useful biological material and also a novel cell source for cell transplantation. The availability of hAECs and hAMSCs and 
the lack of ethical concerns for this source of stem cells are considered advantageous for their widespread use and acceptance.

Cystic fibrosis (CF) is a lethal autosomal recessive disorder due to mutations in the CF transmembrane conductance regulator (CFTR) gene, a cAMP-dependent chloride channel expressed on the apical side of epithelial cells [4]. Although $\mathrm{CF}$ involves many organs with secretory/absorptive properties, including the liver, the main cause of morbidity and mortality is a chronic inflammatory lung disease. Because of its monogenic nature, and since the lung is easily accessible, $\mathrm{CF}$ has been a target disease for gene-based therapeutic intervention; however, this approach has given unsatisfied results in terms of efficiency of gene delivery to the lung and of efficacy outcomes [5]. This partial success was due to the inefficiency of passing the mucus barrier overlying the epithelial cells and to the immune response against the gene therapy vectors [6]. Cell therapy could be a more effective treatment because allogenic normal cells and autologous engineered cells express CFTR gene. Bone marrow-derived stem cells have been the first source evaluated for homing to the lung and curative potential, but the in vivo efficiency of bone marrow stem cells to differentiate in airways epithelium is very low (0.01-0.025\%) [7], as also demonstrated by different studies in CF mice $[8,9]$.

Recently, new cell sources for CF treatment have been characterized; MSCs from cord blood [10] and amniotic fluid stem cells [11] can differentiate in vitro and in vivo in airway epithelium. Stemming from these results on MSCs, and based on the demonstrated high plasticity of amnioticderived stem cells, after an extensive characterization of the expression of phenotypic and pluripotency markers by hAMSCs and their differentiative potential, we preliminarily evaluated their usefulness in CF by in vitro experiments using cocultures of hAMSCs and CF-respiratory epithelial cells.

\section{Materials and Methods}

2.1. Isolation and Culture of Human Amniotic Mesenchymal Stromal Cells. Human amniotic mesenchymal stromal cells (hAMSCs) were isolated from term placentas $(n=3)$ which would normally be discarded after delivery. Tissues were obtained under appropriate Ethical Committee approval and signed informed consent. All infectious pathogen-positive deliveries including those involving HBV, HCV, and HIV, as well as cases of prediagnosed genetic abnormalities, were excluded. Placenta samples were procured immediately after delivery and processed under sterile conditions. After peeling from the placenta and washing with calcium- and magnesium-free HBSS (CMF-HBSS, Lonza, Treviglio, Italy) supplemented with $0.5 \mathrm{mM}$ EGTA (Sigma, Milan, Italy), amnion membranes were processed to remove epithelial cells as previously reported [12]. Once epithelial cells were removed, the amniotic membranes were digested in order to collect hAMSCs [13]. Briefly, amniotic membranes were washed three times with cold HBSS, cut into pieces, and transferred into $50-\mathrm{mL}$ centrifuge tubes, containing about $30-40 \mathrm{~mL}$ of digestion solution composed by EMEM (Lonza) supplemented with $25 \mathrm{mM}$ HEPES buffer without L-glutamine
(Lonza), $1 \mathrm{mg} / \mathrm{mL}$ collagenase type IV, and $25 \mu \mathrm{g} / \mathrm{mL}$ DNase I (both from Sigma, Milan, Italy). Membranes were incubated on a rotator between $45 \mathrm{~min}$ to $1.5 \mathrm{~h}$, depending on tissue thickness, at $37^{\circ} \mathrm{C}$. After blocking the enzymatic reaction with cold HBSS, cell suspensions were centrifuged 2 times for $5 \mathrm{~min}$ at $200 \times \mathrm{g}, 4^{\circ} \mathrm{C}$ and counted using a Bürker chamber.

After isolation, DNA was obtained from hAMSCs and hAECs by phenol/chlorophorm extraction. Purified DNA was investigated for most frequent mutations in CFTR gene using a commercial kit (Inno-Lipa CFTR19, Inno-Lipa CFTR17+TnUpdate, Inno-Lipa CFTR-Italian RegionalInnogenetics, Ghent, Belgium).

hAMSCs were plated at a density of $1 \times 10^{5}$ cells per $\mathrm{cm}^{2}$ in standard culture medium composed by DMEM (Lonza) supplemented with $1 \%$ sodium pyruvate, $10 \%(\mathrm{v} / \mathrm{v})$ heatinactivated fetal bovine serum (FBS), $1 \%$ nonessential amino acid, $55 \mu \mathrm{M} \beta$-mercaptoethanol (all by Invitrogen, Milan, Italy), $1 \%$ L-glutamine, $1 \%$ antibiotics solution (both by Cellgro, Manassas, VA, USA), and $10 \mathrm{ng} / \mathrm{mL}$ epidermal growth factor (EGF, Sigma), according to the previously reported protocol [13]. Medium was replaced $2 \mathrm{~h}$ after plating in order to remove unattached contaminating epithelial cells and then every 2 days.

Every time cells reached $80 \%$ of confluence, cells were detached with trypsin-EDTA (Invitrogen), washed, counted with a Bürker chamber, and replated in a new plastic flask at a density of $1 \times 10^{5}$ cells per $\mathrm{cm}^{2}$ in order to calculate their growth curve. Doubling time was calculated inserting times and cell counts on the website http://www.doubling-time .com/compute.php.

\subsection{Characterization of hAMSCs}

2.2.1. Flow Cytometry. Flow cytometry analyses of hAMSCs were performed immediately after dissociation and at second culture passage as previously described [14]. Briefly, cells were detached from culture flask using trypsin and, after washing, were incubated with $4 \%$ normal mouse serum/PBS/ $\mathrm{NaN}_{3}$ for 20 minutes at $4{ }^{\circ} \mathrm{C}$ in order to block nonspecific sites on cell membrane. Cells were then stained in the dark at $4^{\circ} \mathrm{C}$ for 20 minutes with 7-amino actinomycin-D (7AAD) to discriminate viable cells from fragments and dead cells and with the following monoclonal antibodies (moabs): against CD13, CD29, CD31, CD34, CD44, CD45, CD49f, CD73, CD90, CD105, CD146, CD166, EpCAM, SSEA4 (all from Becton Dickinson Biosciences, BD, Franklin Lakes, NJ, USA), and CD133-1 (Miltenyi Biotech, Bergisch Gladbach, Germany). Moabs were conjugated with fluorescein isothiocyanate (FITC) or phycoerythrin (PE) or PE-Cyanin 7 (PE-Cy7) or allophycocyanin (APC) or APC-Cyanin 7 (APC-Cy7).

For internal labelling, cells were fixed at room temperature with $4 \%$ paraformaldehyde (PFA) for $10 \mathrm{~min}$ and permeated with $100 \%$ ethanol for 2 min after washing with PBS. Cells were incubated with $10 \%$ FBS to block nonspecific binding, followed by primary antibodies against Oct- 4 and Nanog (Santa Cruz Biotechnology, Santa Cruz, CA, USA) for $1 \mathrm{~h}$; secondary PE-conjugated antibody (Invitrogen) was applied for $30 \mathrm{~min}$. The fluorescence threshold between negative and positive cells was set on the basis of the reactivity of 
appropriate nonspecific fluorochrome-conjugated isotypic controls. At least, $10^{6}$ cells were finally analysed using a FACSCanto II equipped with FACSDiva software (BD).

2.2.2. Immunofluorescence Microscopy of Cultured Cells. Plated cells were stained as reported elsewhere [14]. Fixed (4\% PFA or $70 \%$ ethanol for $30 \mathrm{~min}$ ) and permeabilized (HEPESTriton X-100 buffer $0.25 \%$ in PBS for $20 \mathrm{~min}$ ) cells were incubated with a blocking buffer containing $0.5 \mathrm{M} \mathrm{NaCl}$, $20 \mathrm{mM} \mathrm{NaHPO}_{4}, 0.1 \%$ Triton X-100, and 30\% horse and goat serum for $30 \mathrm{~min}$ (all reagents were from Sigma) and then immunostained with the following primary moabs: anti-EpCAM, cytokeratin (CK) 18, alpha-fetoprotein (Sigma), CK19 (Novocastra, Newcastle, UK), albumin (DakoCytomation, Milan, Italy), CK7, CD49f, CD29, S100A4, CD90, CD31, CD146, zonula occludens-1 (ZO-1), fibronectin, alpha1-antitrypsin, E-cadherin, and beta-catenin (BD) for $2 \mathrm{~h}$. After washing, cells were incubated with the appropriate secondary FITC or Texas Red-conjugated antibodies (BD) for $1 \mathrm{~h}$ in the dark. Nuclei were counterstained with $4^{\prime}, 6$-diamidino-2-phenylindole (DAPI, Sigma) for $5 \mathrm{~min}$ in the dark.

Images were taken using a Leica Microsystems DM IRE 2 microscope and analysed with the FW4000I software (Leica Microsystems, Milan, Italy).

\subsubsection{Reverse-Transcriptase (RT)-Polymerase Chain Reaction} $(P C R)$. CFTR mRNA expression was investigated by semiquantitative RT-PCR. Total RNA was isolated from freshly isolated and cultured cells with TRIzol ${ }^{\circledR}$ Reagent (Invitrogen), according to the manufacturer's protocol. One $\mu \mathrm{g}$ of RNA was reverse transcribed into first strand cDNA with the High-Capacity cDNA Reverse Transcription kit (Applied Biosystems) using random primers following manufacturer's instructions. In order to analyze the expression of CFTR gene, $100 \mathrm{ng}$ of cDNA was used in a final volume of $25 \mu \mathrm{L}$ with $200 \mathrm{nM}$ dNTP, $10 \mathrm{pM}$ of each outer primer (Table 1), $0.3 \mathrm{U}$ Taq-DNA-polymerase, reaction buffer, and $\mathrm{MgCl}_{2}$ (Invitrogen). A second nested PCR was performed using inner primers (Table 1). Cycling conditions consisted of $95^{\circ} \mathrm{C}$ for 30 seconds, annealing at $60^{\circ} \mathrm{C}$ for $1 \mathrm{~min}$ and elongation at $72^{\circ} \mathrm{C}$ for $2 \mathrm{~min}$. Cycle numbers consisted of 35 cycles. cDNA from nasal brushing from healthy control was used as positive control for CFTR analysis; no reverse-transcribed sample was used as negative control.

In parallel, $\beta$-actin was used as house-keeping gene (Table 1). PCR products were evaluated on $1.5 \%$ agarose gel electrophoresis.

\subsection{Differentiation of hAMSCs Towards Different Lineages}

2.3.1. Adipogenic and Osteogenic Differentiation. To induce adipogenic and osteogenic differentiation, cells at passages 13 were harvested and plated on tissue culture dishes (BD) at a density of $4 \times 10^{3}$ cells per $\mathrm{cm}^{2}$. Cells were then treated with either adipogenic or osteogenic differentiation media (Lonza) for three weeks. The adipogenic protocol consisted of 4 rounds of adipogenic induction medium for 2 days followed by adipogenic maintenance medium for 3 days. The presence of adipose elements in induced cultures was determined by Oil-Red-O (Sigma) staining as follow: cells were washed in PBS, then fixed in $10 \%$ formalin for $1 \mathrm{~h}$, washed in isopropanol $60 \%$, and air dried. Cells were then incubated with OilRed-O staining solution for $10 \mathrm{~min}$, then washed several times in PBS, and observed with an inverted microscope Eclipse TS100 (Nikon, Tokyo, Japan) equipped with a DS-FI1 CCD camera (Nikon).

In order to induce osteogenesis, cells were treated with osteogenic medium for 3 weeks with medium changes 3 times a week. The presence of calcium deposits in induced cultures was determined by Alizarin Red (Sigma) staining as follow: cells were fixed in $10 \%$ formalin for $1 \mathrm{~h}$, then washed in deionized water, and incubated for $30 \mathrm{~min}$ at room temperature with Alizarin Red $2 \%$ in water at $\mathrm{pH}$ 4.2. The cells were finally washed several times to remove the excess of staining and analyzed as described above.

2.3.2. Hepatocyte Differentiation. A simple protocol [15] was used for hepatic differentiation of hAMSCs; cells were plated on type 1 collagen-coated culture dishes in DMEM supplemented with $10 \%$ FBS, $1 \%$ nonessential aminoacids, $1 \%$ Lglutamine, beta-mercaptoethanol, and $10 \mathrm{ng} / \mathrm{mL}$ of EGF for 8 days and then with IMDM with the same compounds plus $10^{-7} \mathrm{M}$ dexamethasone (Sigma) for 6 days. One of the functions in cultured hepatocytes is that of the cytochrome P450dependent mixed function oxidases (MFOs). Diethoxy $(5,6)$ chloromethylfluorescein (Invitrogen) is a probe suitable for use as an in situ stain for MFO activity since this colorless molecule is metabolized in a fluorescent green compound retained in the cells [16]. Five $\mathrm{mg}$ of probe was eluted in $1143 \mu \mathrm{L}$ DMSO (stock solution $10 \mathrm{mmol}$ ). Test medium was prepared as follow: $987 \mu \mathrm{L}$ of RPMI, $12 \mu \mathrm{L}$ HEPES $1 \mathrm{M}$ (12 mmol final), and $1 \mu \mathrm{L}$ probe $10 \mathrm{mmol}(10 \mu \mathrm{mol}$ final). Control medium was prepared as follow: $987 \mu \mathrm{L}$ RPMI, $12 \mu \mathrm{L}$ HEPES $1 \mathrm{M}$ ( $12 \mathrm{mmol}$ final), and $1 \mu \mathrm{L}$ DMSO. The cells were washed in PBS and incubated with the test (or control) medium for $2 \mathrm{~h}$ at $37^{\circ} \mathrm{C}$ in a $\mathrm{CO}_{2}$ incubator. Cells were analyzed using a Leica Microsystems DM IRE 2 microscope.

After differentiation for 21 days (8 days in DMEM supplemented as above +13 days in IMDM supplemented with dexamethasone), cells were stained by means of immunofluorescence as reported above in order to verify the expression of epithelial markers.

2.4. hAMSC Labelling. Passage two hAMSCs were labeled with chloromethylbenzamido (CellTracker CM-DiI) [17]. Stock solutions of CM-DiI were prepared in dimethylsulfoxide (DMSO) at $1 \mathrm{ng} / \mu \mathrm{L}$. Immediately before labelling, the stock solution was diluted up to a final concentration of $0.005 \mathrm{ng} / \mu \mathrm{L}$ in DMEM without phenol red. Cells grown at confluence in a T25 flask were washed with phosphate-buffered saline (PBS) and then incubated with the dye working solution for $30 \mathrm{~min}$ at $37^{\circ} \mathrm{C}$. After labelling, cells are washed twice with PBS, then incubated at $37^{\circ} \mathrm{C} 5 \% \mathrm{CO}_{2}$ for at least $24 \mathrm{~h}$ in the presence of fresh medium. 
TABle 1: Primer sequences for CFTR RT-PCR analysis.

\begin{tabular}{lccc}
\hline Gene & \multicolumn{1}{c}{ Forward primer } & Reverse primer & Product length (bp) \\
\hline CFTR & & & 1108 \\
Outer primers & CGAGAGACCATGCAGAGGTC & GCTCCAAGAGAGTCATACCA & 301 \\
Inner primers & CGAGAGACCATGCAGAGGTC & TGTACTGCTTTGGTGACTTCCCC & 610 \\
$\beta$-actin & CAACTGGGACGACATGGA & ACGTCACACTTCATGATGGA & \\
\hline
\end{tabular}

2.5. Cultures of Airway Epithelial Cells. 16HBE14o- and CFBE41o- are human epithelial bronchial cell lines, wild type and homozygous for the F508del allele (F508del/F508del), respectively, a generous gift of Professor D. Gruenert (University of California at San Francisco, USA). Epithelial cells were grown in MEM, $10 \% \mathrm{FBS}, 100 \mathrm{U} / \mathrm{mL}$ penicillin, and $100 \mathrm{U} / \mathrm{mL}$ streptomycin, alone or in Coculture with hAMSCs.

2.6. Coculture of hAMSCs with CFBE41o-Cells. Labelled hAMSCs were mixed with CFBE41o- cells at different ratios $(1: 5,1: 10,1: 15$, and $1: 20)$ and, in order to obtain polarized cocultures, cells were seeded on 6.5-mm diameter Snapwell, $0.4-\mu \mathrm{m}$ pore size (Corning, Acton, MA, USA) at $1 \times 10^{5}$ per filter coated with a solution of $10 \mu \mathrm{g} / \mathrm{mL}$ fibronectin (BD Biosciences, CA, USA), $100 \mu \mathrm{g} / \mathrm{mL}$ albumin from bovine serum (Sigma-Aldrich, Milan, Italy), and $30 \mu \mathrm{g} / \mathrm{mL}$ bovine collagen type I (BD) dissolved in MEM. As controls, hAMSCs and CFBE41o- were seeded at $2.5 \times 10^{4}$ and $1 \times 10^{5}$ per filter, respectively. Cocultures were maintained at $37^{\circ} \mathrm{C} 5 \% \mathrm{CO}_{2}$ for at least 6-8 days.

Separate cocultures were obtained by seeding hAMSCs onto the filter and CFBE41o- cells onto the bottom of the lower chamber. To obtain $1: 5$ and $1: 10$ ratios, hAMSCs were seeded at $2 \times 10^{4}$ and $1 \times 10^{4}$ and CFBE41o- cells at $8 \times 10^{4}$ and $9 \times 10^{4}$, respectively. As controls, hAMSCs were seeded at $1 \times 10^{5}$ per filter. Medium was changed daily in each chamber for 5 days, and cultures were analyzed at day 6 .

2.7. CFTR Cytofluorimetric Assay. Cells were detached with trypsin-EDTA treatment and fixed in PBS containing 2\% PFA for $5 \mathrm{~min}$. After centrifugation at $250 \times \mathrm{g}$, the resulting pellets were washed and resuspended in PBS. The cells were then incubated with CFTR antibody MAB25031 mouse IgG2a (R\&D Systems, Minneapolis, MN, USA) used at $1: 20$ dilution for $1 \mathrm{~h}$ at $4^{\circ} \mathrm{C}$. After washing in PBS, the cells were incubated with the FITC-conjugated secondary antibody (anti-mouse used at 1:100; Sigma) for $1 \mathrm{~h}$ at $4^{\circ} \mathrm{C}$, followed by two washes in PBS, and analyzed. As a background control, cocultures were incubated with secondary antibody only, and the resulting fluorescence was subtracted from the analyzed samples incubated both with primary and secondary antibodies. Data were collected using a Coulter Epix XL flow cytometer (Beckman Coulter, Fullerton, CA, USA) and analyzed with WinMDI 2.9 (http://www.cyto.purdue.edu/ flowcyt/software/Winmdi.htm). Ten thousand cells were examined in each experiment. Since physical parameters (forward scatter and side scatter) did not allow us to distinguish hAMSCs from CFBE41o- cells, specific expression of CFTR on hAMSCs was detected in the CM-DiI-labelled cells. Analyses were performed by plotting the FLH- 1 channel ( $525 \mathrm{~nm}$ ) against the FLH-2 channel ( $575 \mathrm{~nm}$ ), identifying the CFTRspecific green signal and the red-labelled hAMSCs, respectively. The vitality was evaluated by trypan blue exclusion assay and resulted to be $>98 \%$.

2.8. Confocal Analysis of CFTR Protein. Polarized cells were washed three times with PBS and incubated in PBS, 2\% BSA for $30 \mathrm{~min}$ on ice. Cells were incubated with CFTR antibody MAB25031 diluted $1: 20$ in PBS containing 0.2\% BSA for $1 \mathrm{~h}$ on ice. Cells were rinsed three times with PBS and incubated with the FITC-conjugated secondary antibody diluted $1: 100$ in PBS added with $0.2 \%$ BSA for $30 \mathrm{~min}$ on ice. After two washes in PBS, cells were fixed in 3\% PFA and 2\% sucrose for $10 \mathrm{~min}$. After three washes in PBS, filters were excised and placed side up on a glass slide and overlaid with a drop of Mowiol (Calbiochem, San Diego, CA, USA) followed by a coverslip. Cells were analyzed using a Nikon TE2000 microscope coupled to a Radiance 2100 confocal dual-laser scanning microscopy system (Bio-Rad, Segrate, Italy). Specimens were viewed through a 60x oil immersion objective. Digital images were processed using the program Laser Sharp 2000 (Bio-Rad).

2.9. Statistical Analysis. Statistical significance of differences was evaluated by a two-tailed unpaired Student's $t$-test. Data were analyzed using Prism 4 (GraphPad Software, Inc., La Jolla, CA, USA). $P$ values of less than 0.05 were considered significant.

\section{Results}

3.1. Isolation and Characterization of hAMSCs from Human Amnion. At least $33 \times 10^{6}$ hAMSCs (range $26-160 \times 10^{6}$ ) were recovered in each isolation $(n=3)$ with a viability of 85-90\%. Inno-lipa screening revealed the absence of most frequent mutation of CFTR ( $86 \%$ of detection rate) in hAMSCs used in this study. After plastic adhesion, hAMSCs were characterized by a fibroblastic morphology very similar to that described for mesenchymal cells isolated from bone marrow (Figures 1(a) and 1(b)) and could be kept in culture until passages 5-10. Proliferation slowed beyond passage two. In the exponential growth phase, approximately two cell doublings were observed over 15 days, giving these cells an average doubling time of 18.03 days calculated over 28 days of culture. An example of a growth curve for hAMSCs is presented in Figure 1(c). 


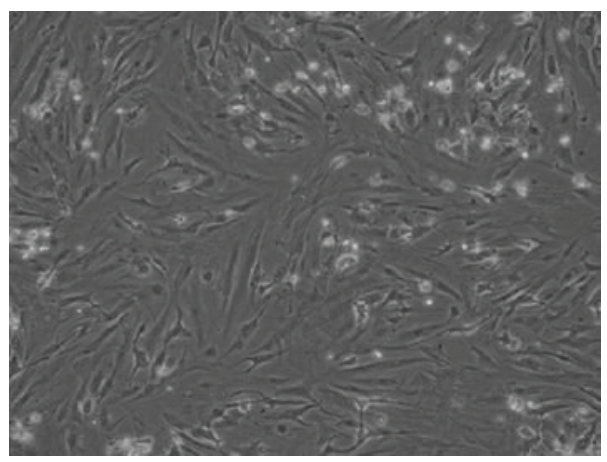

(a)

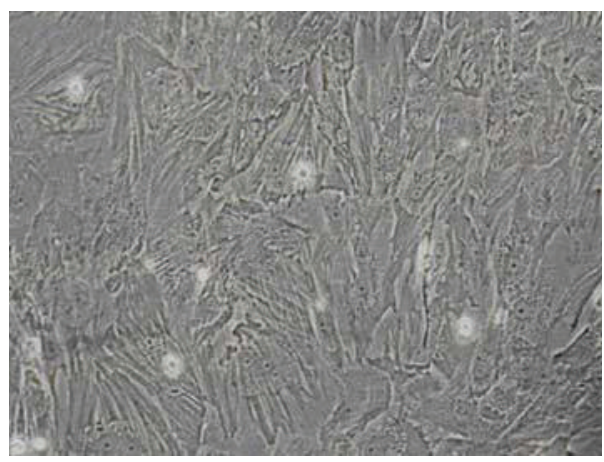

(b)

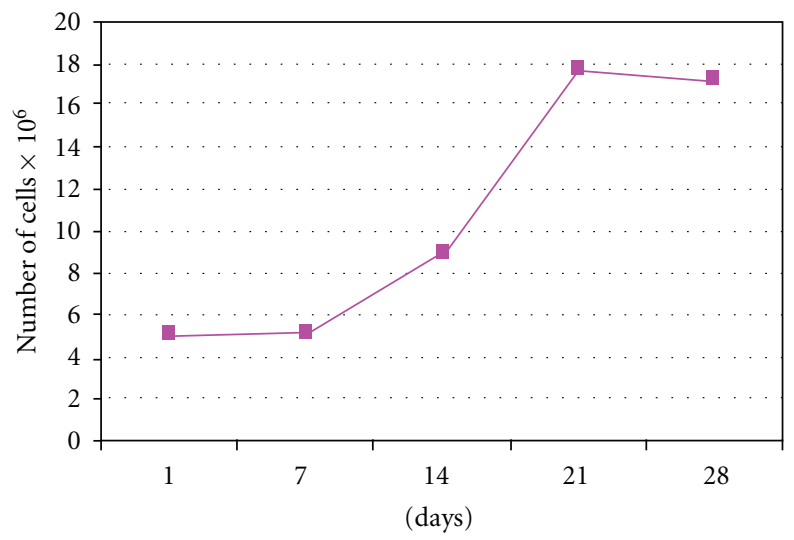

(c)

Figure 1: hAMSCs morphology and growth. Cell morphology at passage one (a) and passage three (b), original magnification 10x. Growth kinetics of hAMSCs in culture (c).

3.2. Flow Cytometry and Immunofluorescence Analysis. hAMSCs showed an immunophenotypic profile very similar to that of mesenchymal stem cells derived from bone marrow; that is, they are positive for CD29, CD44, CD73, CD90, and CD105 and negative for the hematopoietic markers CD34, CD133, and CD45. Freshly isolated hAMSCs showed a low expression of epithelial markers (EpCAM and CD49f), which decreased up to null expression after the first passage (Table 2).

hAMSCs showed the embryonic stem cell associated surface marker SSEA4 (Figure 2(f)), while very low expression of molecular markers associated with pluripotent stem cells (Nanog and Oct-4) by flow cytometry was observed (Figures 2(d) and $2(\mathrm{e}))$.

Fluorescence microscopy confirmed the positivity for CD29 and CD90 and revealed the expression of other mesenchymal markers such as fibronectin and vimentin (Figure 3 ). hAMSCs were almost negative for ZO-1, a marker of tight junctions and cytokeratin (CK) 7, while stained positive for CK18.

3.3. Cell Differentiation Ability. To determine whether hAMSCs could differentiate into adipocytes, cells were allowed to grow to $70 \%$ confluence prior to induction. Morphological changes as well as formation of lipid droplets within the cells were noticeable starting from one week after induction and were visualized by Oil-Red-O staining (Figure 4(b)). Cells maintained in control medium did not show any sign of adipogenic differentiation (Figure 4(a)).

To investigate the osteogenic potential of hAMSCs, cells were cultured under appropriate condition for differentiation. The presence of calcium deposits in induced cultures was determined by Alizarin Red (Figure 4(d)). Cells maintained in control media did not show any change in their morphology and no calcium deposit (Figure 4(c)).

Hepatocyte differentiation of hAMSCs was evaluated after 14 days of induction. Cells were incubated for $2 \mathrm{~h}$ with diethoxy $(5,6)$ chloromethylfluorescein. The generation of fluorescent products was evaluated by fluorescence microscopy. Although hAMSCs were of mesenchymal origin, they showed signs of hepatocyte differentiation (Figure 4(f)). Cells maintained in control medium did not show any sign of hepatocyte differentiation (Figure 4(e)).

Moreover, we performed cell immunophenotyping after hepatocyte induction (Figure 5). After hepatocyte differentiation, the number of cells expressing CK7 increased, while some cells expressed albumin and, weakly, alpha1-antitrypsin. Finally, we observed also the presence of CK19- positive cells. No alpha-fetoprotein expression was detected (not shown).

3.4. CFTR mRNA Expression. In order to see whether hAMSCs express CFTR mRNA, a semiquantitative RT-PCR 


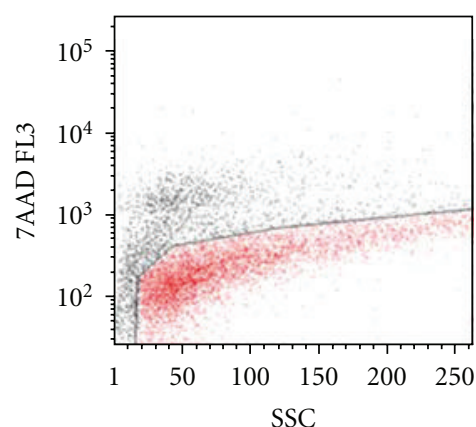

(a)

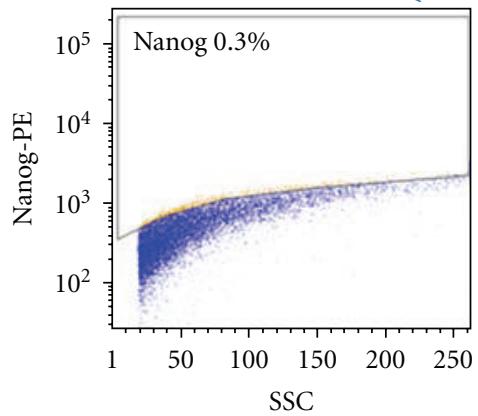

(d)

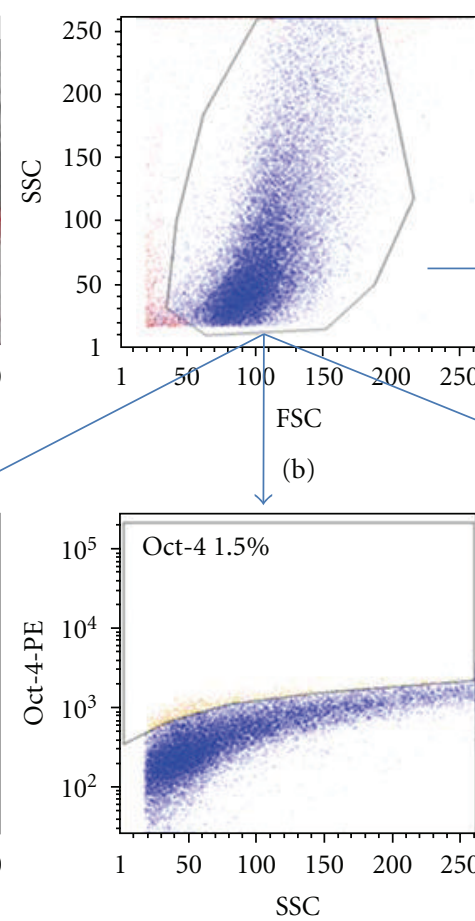

(e)

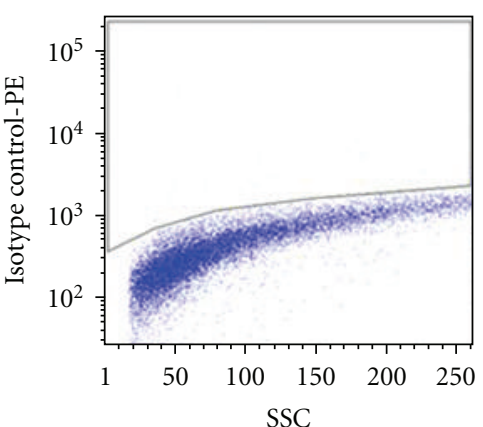

(c)

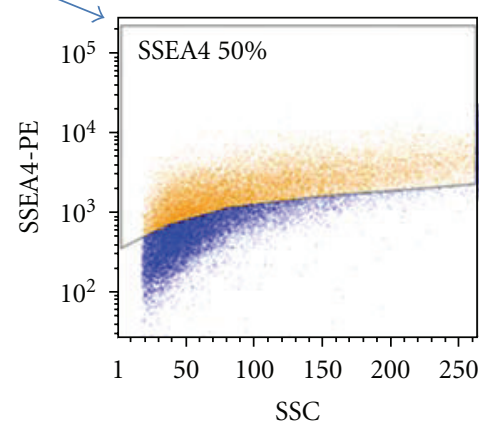

(f)

FIgURE 2: hAMSCs pluripotent stem cells and ESC marker expression. Flow cytometry representative expression of the pluripotent and embryonic stem cells markers in freshly isolated hAMSCs. (a) For each staining, a gate on viable cells (red) was drawn; (b) hAMSCs were gated on the basis of morphological features; (c) cells incubated with isotypic control were used as negative controls; (d) Nanog, (e) Oct-4, and (f) SSEA4 expression in hAMSCs.

TABLE 2: hAMSCs membrane marker expression.

\begin{tabular}{|c|c|c|c|c|}
\hline \multirow{2}{*}{ Surface antigens } & \multicolumn{2}{|c|}{ Freshly isolated } & \multicolumn{2}{|c|}{ Passage two } \\
\hline & Median \% & Range & Median \% & Range \\
\hline CD45 & 2 & $0-4$ & 4 & $3-4$ \\
\hline CD34 & 0 & $0-1$ & 0 & $0-1$ \\
\hline CD133 & 0 & $0-1$ & 0 & $0-1$ \\
\hline CD13 & 80 & $70-89$ & 95 & 89-99 \\
\hline $\mathrm{CD} 44$ & 81 & $71-90$ & 90 & 89-92 \\
\hline CD73 & 90 & $88-91$ & 94 & $88-99$ \\
\hline CD90 & 79 & $69-89$ & 94 & 89-99 \\
\hline $\mathrm{CD} 29$ & 76 & $66-86$ & 98 & $95-99$ \\
\hline CD105 & 49 & $30-66$ & 58 & $40-76$ \\
\hline CD166 & 83 & $71-95$ & 85 & $71-98$ \\
\hline CD49f & 16 & $13-31$ & 3 & $2-5$ \\
\hline ЕрСАM & 16 & $12-20$ & 0 & $0-1$ \\
\hline CD31 & 0 & 0 & ND & $\mathrm{ND}$ \\
\hline CD146 & 0 & 0 & ND & ND \\
\hline
\end{tabular}

Data were expressed as median percentage and ranges of three different experiments.

assay was carried out. CFTR was detected in hAMSCs by RT-PCR only after nested PCR (Figure 6). The expression of CFTR in hAMSC appeared to decrease dramatically during culture. hAECs showed a similar expression of CFTR mRNA when studied upon isolation (Figure 6).
3.5. CFTR Protein Expression by Flow Cytometry. hAMSCs stained with CM-DiI (as described in Materials and Methods section) were mixed with CFBE41o- cells at different increasing ratios $(1: 20,1: 15,1: 10$, and $1: 5)$ and seeded onto semipermeable filters. In order to analyze the CFTR protein 

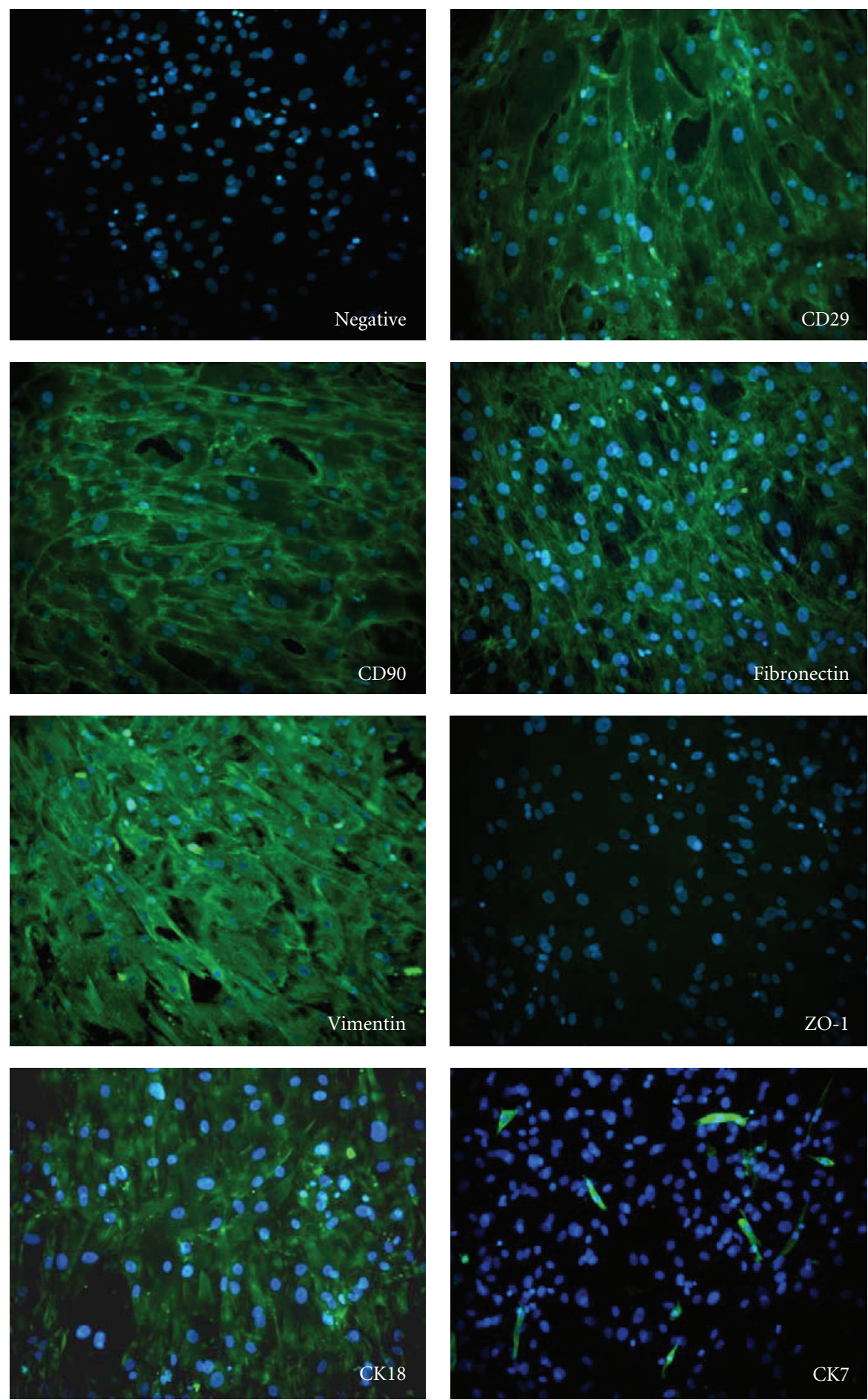

FIGURE 3: Immunofluorescence characterization of hAMSCs. Representative images of fluorescence microscopy staining. The upper left panel (denoted as "negative") shows cells incubated with the secondary antibody only. hAMSCs were positive for CD29, CD90, fibronectin, vimentin, and CK 18 and negative for ZO-1 and CK 7. Nuclei were counterstained with DAPI. Original magnification 20x.

expression in hAMSC-CFBE41o- cocultures at different ratios, a flow cytometric assay was performed. This mixed population was analyzed after labelling with the CFTR antibody MAB25031 in the absence of permeabilization followed by an incubation with FITC-conjugated secondary antibody. As a positive control, CFTR labelling was assessed in normal human airway $16 \mathrm{HBE} 14 \mathrm{o}-$ cells, resulting in $50 \pm 5.0 \%$ of positive cells, as previously shown [18]. CFBE41o- cells showed less CFTR-specific labelling on the membrane (11\% of positive cells), consistent with the lack of CFTR transport on the plasma membrane which is a characteristic of these cells. Plasma membrane CFTR expression was detected in 


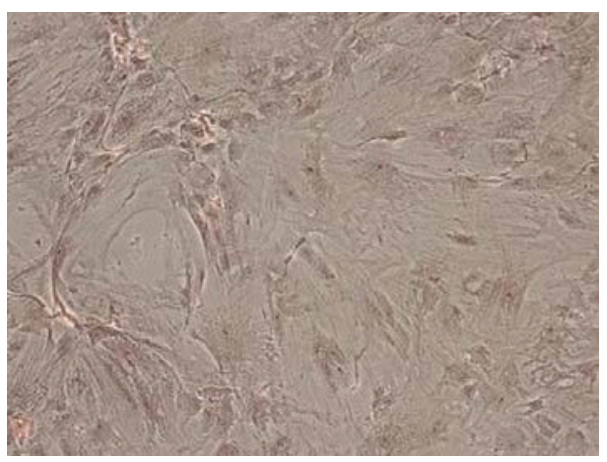

(a)

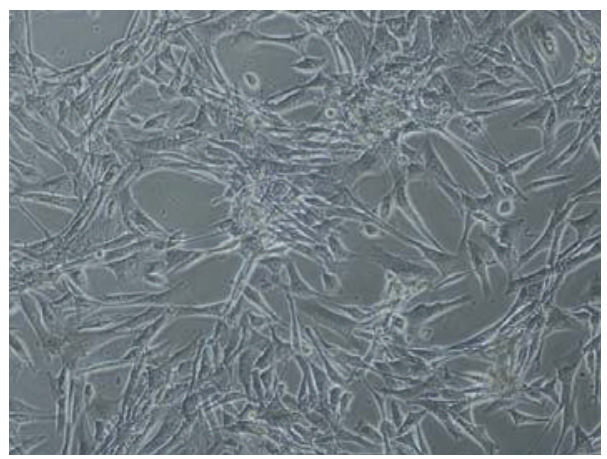

(c)

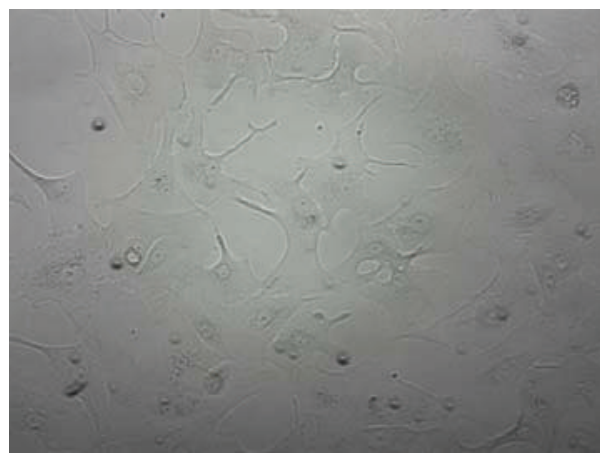

(e)

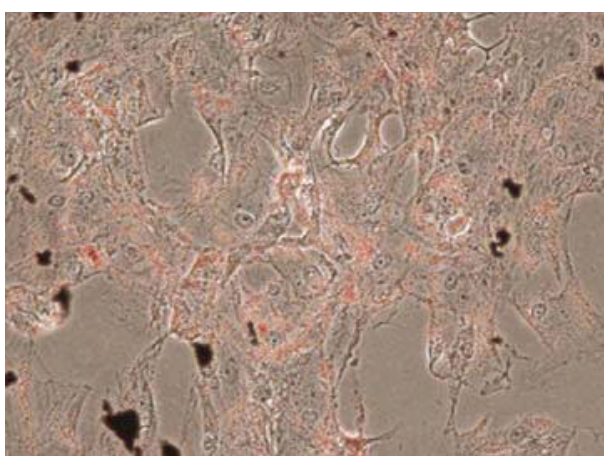

(b)

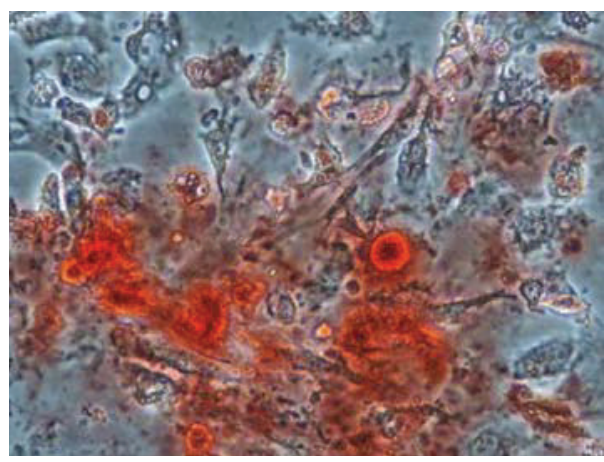

(d)

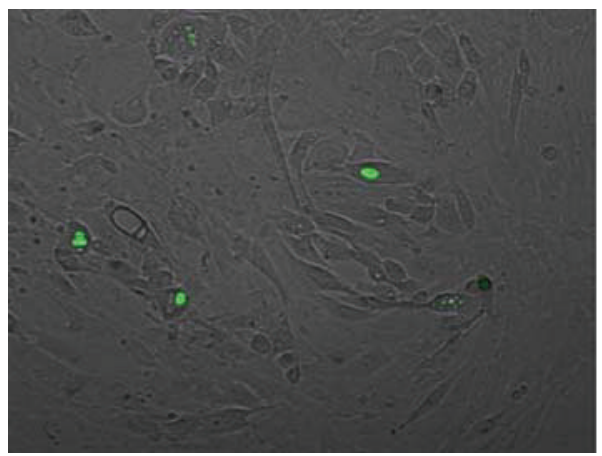

(f)

FIGURE 4: In vitro differentiation capability. Representative images of in vitro osteocyte (b), adipocyte (d), and hepatocyte (f) differentiation of hAMSCs. (a), (c), and (e) represent respective negative controls (i.e., uninduced cells). Original magnification 20x.

only $6.2 \%$ of hAMSCs (Table 3 ). It was possible to detect an increase of CFTR-specific signal in CM-DiI-labeled cells at all hAMSC-CFBE41o- ratios as compared with hAMSCs cells alone. The lower the ratio of hAMSCs: CFBE41o- the lower the increase in CFTR-specific signal in CM-DiI-labeled cells, these data indicating that a critical number of hAMSCs is important in order to obtain a meaningful effect on CFTR expression. Overall, these data show that a population of hAMSCs with low CFTR expression have increased this expression upon cocultures with CF epithelial cells.

To investigate the mechanism underlying the expression of CFTR in hAMSCs after cocultures with CFBE41o- cells, we performed separate cocultures of hAMSCs and CFBE41ocells. Thus, hAMSCs were grown onto the filter whereas CFBE41o- cells were seeded onto the bottom well. After 6 days of culture, hAMSCs were analyzed for CFTR expression by cytofluorimetry. Results showed that, at the hAMSCs : CFBE41o- ratios of $1: 5$ and $1: 10$, the percentages of CFTR ${ }^{+}$ hAMSCs were $10.5 \pm 3.8$ and 11.6 \pm 5.0 , respectively $(n=3)$. These data, compared with those obtained in direct Coculture conditions (column "\% of $\mathrm{CFTR}^{+}$in whole CM-DiI" population" of Table 3 ), indicate that a direct contact between hAMSCs and CFBE41o- is necessary to obtain a significant increase of CFTR-specific signal in hAMSCs.

3.6. CFTR Expression and Localization by Confocal Microsco$p y$. To confirm cytofluorimetric data and to analyze CFTR expression in cell compartments, hAMSC-CFBE41o- cocultures were assayed by means of confocal microscopy. In previously published work [19], we showed that CFTR protein is expressed on the apical side of $16 \mathrm{HBE} 14 \mathrm{o}$-cells, while 


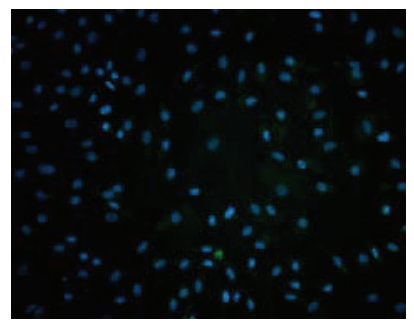

(a)

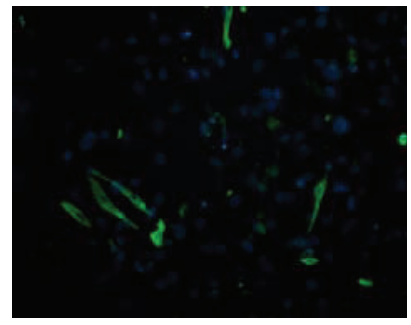

(b)

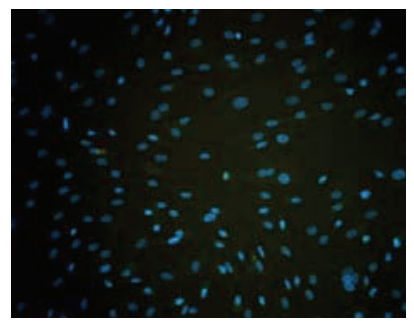

(c)

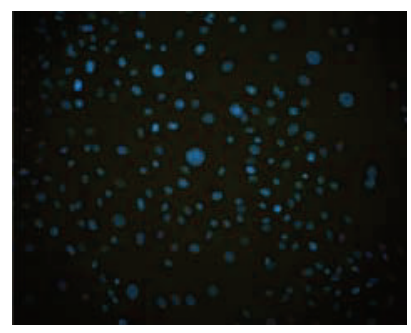

(d)

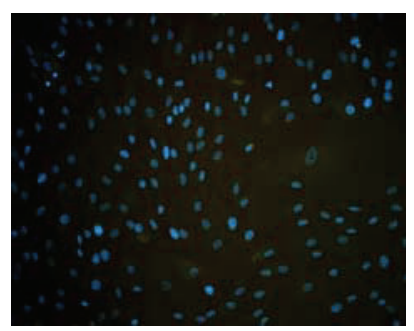

(e)

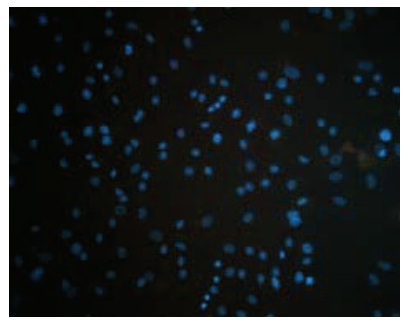

(f)

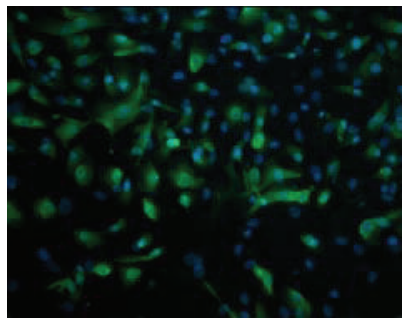

(g)

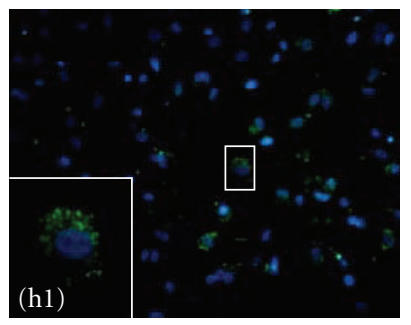

(h)

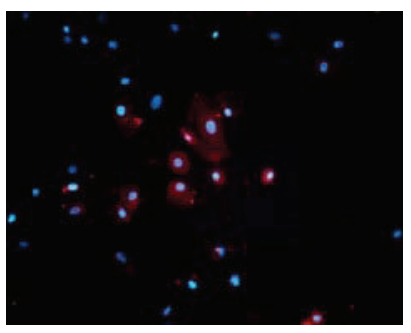

(i)

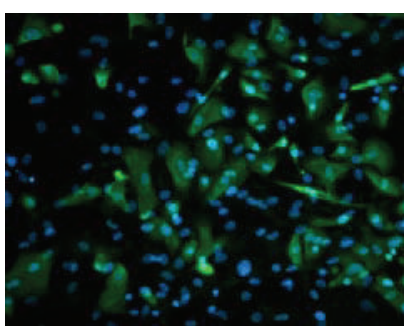

(j)

FIGURE 5: Immunophenotype of mesenchymal stem cells prior (left) and after (right) hepatocyte differentiation for 21 days. (a-f) negative controls, (b-g) CK7, (c-h) albumin, (d-i) alphal-antitrypsin, and (e-j) CK19. Original magnification 20x. The insert h1 represents an enlargement of the cell highlighted by the white square. 
hAMSCs
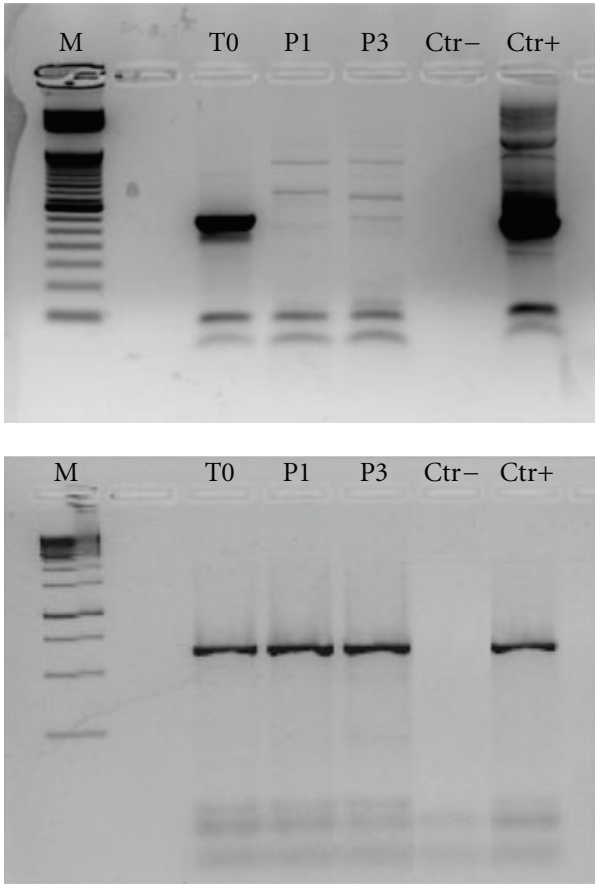

hAECs
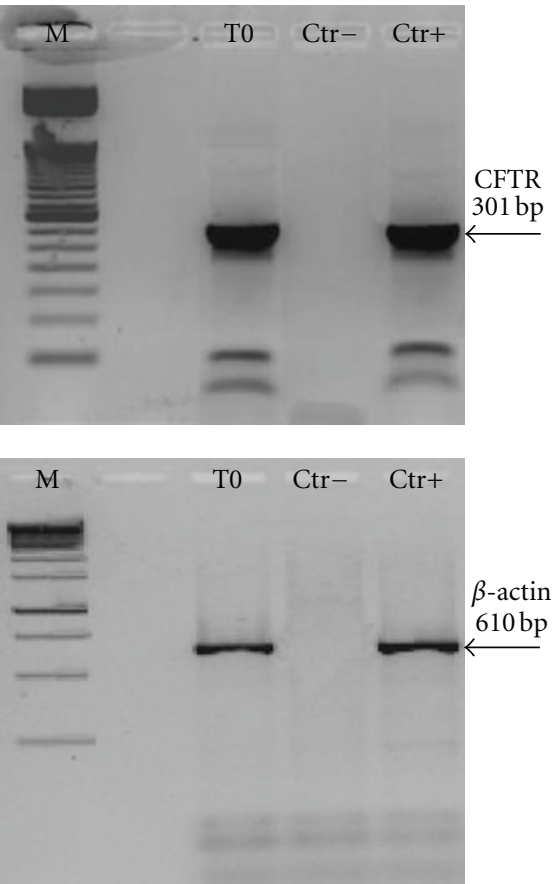

FIgURE 6: CFTR mRNA expression in hAMSCs and hAECs. CFTR on hAMSCs and hAECs upon isolation (T0) and on hAMSCs at passages one (P1) and three (P3). Upper panels: CFTR; lower panels: $\beta$-actin. M: molecular weight markers; Ctr+: positive control (nasal brushing); Ctr-: negative control (no RT). On the right, arrows indicate the specific band along with PCR-product length.

TABLE 3: Percentages of CFTR ${ }^{+}$hMSCs labelled with CM-DiI in cocultures with CFBE41o- cells.

\begin{tabular}{lccc}
\hline & \% of CM-DiI ${ }^{+}$CFTR $^{+}$cells & \% of CFTR ${ }^{+}$in whole CM-DiI ${ }^{+}$population & $P$ \\
\hline hAMSCs & - & $6.2 \pm 2.0$ & - \\
CFBE & - & $11.2 \pm 1.3$ & 0.0006 \\
hAMSC-CFBE $1: 5$ & $12.1 \pm 2.5$ & $50.0 \pm 6.1$ & $<0.0001$ \\
hAMSC-CFBE $1: 10$ & $7.5 \pm 2.1$ & $46.7 \pm 9.3$ & $<0.0001$ \\
hAMSC-CFBE $1: 15$ & $3.0 \pm 0.4$ & $33.2 \pm 6.5$ & $<0.0001$ \\
hAMSC-CFBE $1: 20$ & $2.2 \pm 0.9$ & $34.6 \pm 8.7$ & $<0.0001$ \\
\hline
\end{tabular}

Percentages of CM-DiI ${ }^{+} \mathrm{CFTR}^{+}$cells were obtained by plotting the FLH-1 channel, identifying CFTR-specific green signal, against FLH-2 channel, identifying red-labelled hAMSCs. Percentages of CFTR-expressing hAMSCs in whole CM-DiI ${ }^{+}$population were obtained by dividing the double positive hAMSCs for all $\mathrm{CM}_{-} \mathrm{DiI}^{+}$cells (with and without green signal). Data are shown as the mean $\pm \mathrm{SD}$ of five experiments. Significance is referred to CFTR ${ }^{+}$cells in the whole CM-DiI ${ }^{+}$population in all conditions as compared with hMSCs alone.

CFBE41o- cells display only intracellular staining. CFTR expression and localization was evaluated by epifluorescence with a protocol which allows to detect only surface and not intracellular CFTR (see Materials and Methods section), followed by confocal microscopy analysis. As can be seen in Figure 7, CFTR was highly expressed on the apical membrane of some hAMSCs since red labelled cells showed a green staining at membrane level (Figures $7(\mathrm{~b})-7(\mathrm{~d})$ ), whereas CFBE41o- monolayers in absence of hAMSCs showed essentially no specific signal for CFTR expression on the membrane (Figure 7(a)), consistent with the lack of CFTR transport to the apical membrane in CF cells. hAMSCs showed a very faint signal related to CFTR (Figure 7(e)). These data confirm cytofluorimetric analysis as to the plasma membrane expression of CFTR in labelled hMSCs which increases when Cocultured with CF cells.

\section{Discussion}

Human MSCs are pluripotent stem cells initially identified in postnatal bone marrow (BM) [20], which is the most common source used in clinical settings [21]. However, the use of $\mathrm{BM}$ has some limitations, including the low frequency of MSCs and the invasive procedure for obtaining them. Moreover, the age and disease state may affect the collection of sufficient healthy autologous BM for transplantation [22-24]. Finally, expansion of autologous BM cells could represent a cumbersome and low-yield approach. In the present study, we directed our attention on a source, the amniotic membrane, which is rich in MSCs [25], is easily accessible and ethically acceptable, since the term placenta is discarded after delivery. hAMSCs have been shown to be superior in proliferation and differentiation potential to BM cells [26] and to 


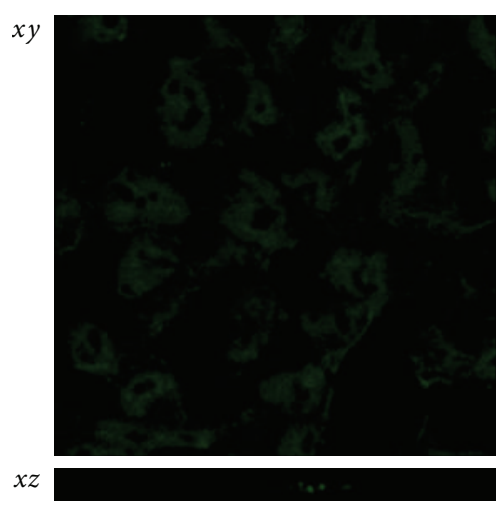

(a)

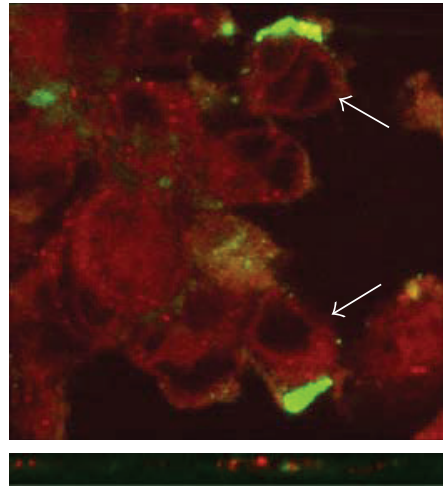

(b)

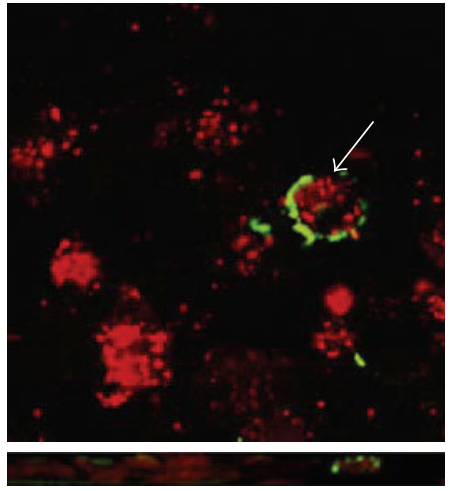

(c)

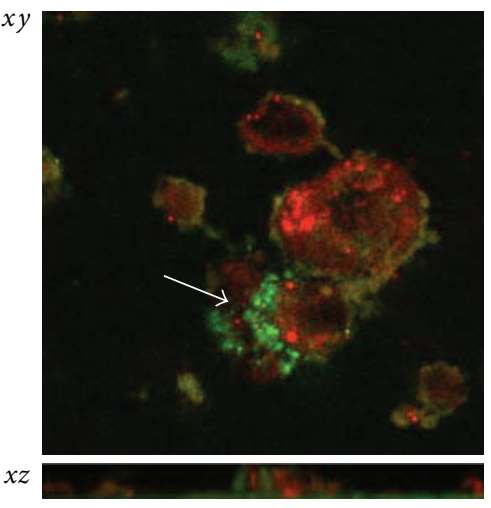

(d)

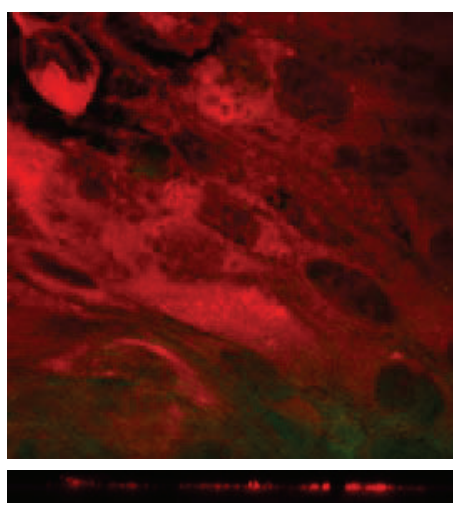

(e)

FIGURE 7: CFTR immunodetection by confocal analysis. Confocal scans are shown in the horizontal cross-section ( $x y)$ plane and vertical cross-section $(x z)$ plane. (a) CFBE41o- cells; (b) hAMSCs- CFBE 1:5 ratio; (c) hAMSCs- CFBE $1: 10$ ratio; (d) hAMSCs- CFBE $1: 15$ ratio; (e) hAMSCs alone. The white arrows point to CM-DiI-labelled hAMSCs expressing CFTR on their membrane (green signal). Note in (d) that hAMSCs harbour some CFTR-specific signal in discrete regions under the apical plasma membrane.

display differentiation potential towards mesoderm lineages (osteogenic, chondrogenic, and adipogenic) similar to BM cells [25-27]. Importantly, various studies have reported differentiation of hAMSCs to ectoderm (neural) [27, 28], mesoderm (skeletal muscle, cardiomyocytic, and endothelial) [26, 29-31], and endoderm (pancreatic) [32] lineages.

In the present study, we isolated and characterized hAMSCs according to previously published protocols, that is, by removing the epithelial cells by enzymatic digestion and obtaining the hAMSC suspension by collagenase and DNase treatment $[26,27,30,33,34]$. hAMSCs show a higher proliferative potential than BM MSCs $[26,35]$, and, in our culture conditions, they reached a plateau after 21 days in culture, similarly to what has been seen in a previous study [26], while others have observed a plateau already at day 11 [25]. hAMSCs displayed a fibroblastic morphology and presented surface markers expressed also by BM-MSCs and cells isolated from both the amnion and other regions of the full-term placenta such as CD29, CD44, CD105, CD73, CD90, and vimentin and were negative for the hematopoietic markers CD45 and CD34 [26, 27, 35-39]. They also displayed positivity for the epithelial markers CD49f and CK18; since these markers are lost upon culture, they could represent a small contamination by epithelial cells, which has been described also previously [33, 40]. This hypothesis is corroborated by
CFTR mRNA expression in hAECs upon their isolation from the placenta (as shown in Figure 6). Interestingly, it has been observed that adherent cells obtained from human amniotic membranes were comprised of both round-shaped epithelial cells and spindle-shaped fibroblast-like cells prior to the first passage, whereas the epithelial cells were rarely detected after the third passage [37]. In alternative, this hybrid phenotype of hAMSCs [41] is interpreted as a sign of pluripotency and suggests that the amnion-derived cells had not completely differentiated into epithelial or mesenchymal cells [3]. Nevertheless, as shown here, the amniotic cells derived from term placenta seem to remain somewhat "plastic" and maintain the capability to differentiate and contribute to cells from different germ layers. Mesodermal differentiation of MSC from various sources was widely reported in the literature and is considered one of the principal assay to prove "stemness" of mesenchymal cells $[20,22,29]$. Not differently from previous papers, hAMSCs isolated in our experiments were able to differentiate into both adipocytes and osteocytes. In recent years, the exploitation of adipose tissue or bone marrow-derived MSC for hepatocyte differentiation and liver repair was explored by many researchers [42-44] but, to the best of our knowledge, only one previous study has demonstrated that hAMSCs can differentiate into hepatocyte-like cells, although only at gene-expression level [37]. 
Because amniotic cells can differentiate into different cell types, we examined them with antibodies directed against well-known surface markers characteristic of embryonic stem cells. Amniotic cells express the stage-specific embryonic antigen SSEA-4 [45] although the relative proportion of SSEA-4-positive cells in initial isolates is lower than that observed with embryonic stem cells [46]. In addition to characteristic stem cell surface markers, amniotic cells show very low expression of Oct-4 and Nanog, transcription factors involved in regulating ES cells' self-renewal and differentiation, as it has been previously shown for freshly isolated MSCs obtained from bone marrow, adipose tissue, and heart [47]. Further studies are needed to understand whether these genes are regulated during the in vitro culture conditions, so to identify regulatory pathways that mimic in vivo activation.

CF is a potential model disease for stem cell therapy because of the persistent lung inflammation that leads to damage and remodeling and can promote engraftment of stem cells [7]. A developing potential therapeutic approach for CF and other lung diseases has been stimulated by recent reports demonstrating that several cell populations derived from adult bone marrow, from amniotic fluid or from umbilical cord blood, including MSCs, endothelial progenitor cells, and circulating fibrocytes, can localize to the lung and acquire phenotypic and functional markers of mature lungspecific cells $[10,11,48]$. The results published by Wang et al. [49] and Loi et al. [8] strongly suggest that the population of $\mathrm{BM}$ cells relevant for repopulating the lung epithelium may be found in the plastic adherent stromal cell compartment. Besides the drawbacks presented by BM-MSCs discussed above, amniotic fluid contains a heterogeneous population of cells from fetal origin [25], whereas MSCs could not be reliably isolated from all term umbilical cordon blood samples [10, 50-52].

In the present study, we propose human placenta as an ethical source of MSCs for CF therapy. The first goal was to investigate the CFTR expression in these cells. At the earliest stages of human development, CFTR protein and function have been detected in early blastocysts in the apical membrane of trophectoderm cells, while its expression at mRNA level has been shown in first trimester placenta (8-week gestation) [53]. However, no data are available concerning its mRNA and protein levels in specific cell types of term placenta. In this study, we show that a nested RT-PCR was necessary for obtaining a detectable signal from freshly isolated hAMSCs, indicating very low levels of CFTR mRNA in these cells. We have recently shown that also hematopoietic stem/ progenitor cells display such low levels upon purification from the bone marrow [18]. The reason why CFTR must be kept at low expression levels in stem/progenitor cell compartments is not known at the moment. Although at this moment we do not know whether freshly isolated hAMSCs show CFTR expression or the specific band by RT-PCR is given by an epithelial contamination, CFTR mRNA was barely visible at passages one and three. Confocal microscopy confirmed these results at the protein level. Notably, CFTR was reexpressed by hAMSCs upon Coculture with epithelial cells, as demonstrated unequivocally by flow cytometry and confocal microscope analysis. At this stage, we do not know why the lower the hAMSCs: CFBE41o- ratios the lower the CFTR expression in hAMSCs. It can be speculated that this effect might be due to cross-talk between amniotic and epithelial cells, for which a critical number of hAMSCs are needed. Indeed, in other Coculture systems, developed with MSCs and chondrocytes, it has been shown universally that the more chondrocytes the lower the expression of extracellular matrix genes and functional properties of engineered cartilage [54, 55].

Also, the mechanism underlying this effect is to be discovered yet. However, indirect cocultures data give us an indication that this effect is primarily due to the contact between amnion MSCs and epithelial cells, and not to factors acting by a paracrine manner. Lung morphogenesis is an orchestrated molecular and cellular process controlled by cellular interactions with growth factors and morphogenic factors [56]. Since the cellular interactions between epithelial and mesenchymal cells in monolayer Coculture are likely to be bidirectional, a possible mode of action could be crosstalk between cells via gap junctions, which has been observed in vivo in the lung between transplanted MSCs and resident epithelial cells [57]. Recently, it has been found that MSCs could be induced to differentiate into corneal epithelium [58] or endothelium [59] in Coculture condition, but not in the indirect Coculture system where MSCs and endothelial cells were cultured in separate inserts [59]. More importantly, BM-MSCs acquired an airway epithelium phenotype when Cocultured with respiratory epithelial cells and determined a partial resumption of the chloride secretion defect in CF epithelia [49]. Although we have not analyzed the correction of the chloride transport defect in CFBE14o- monolayers by hAMSCs, based on the work by Wang et al. [49], it can be anticipated that we should see the same effect on the basic electrophysiological defect. Furthermore, since only 6-20\% of corrected cells are needed to revert the basic defect in chloride secretion [60], our data showing that $33-50 \%$ of hAMSCs acquired CFTR expression shed a positive light on the use of amnion MSCs in the CF treatment.

\section{Conclusions}

Our data indicate hAMSCs as a novel, promising, readily accessible, and ethically compatible source of pluripotent cells that could be used in regenerative medicine. In this respect, hAMSCs present promising features as indicated by their expression of embryonic stem cell markers such as SSEA4 and by their differentiation potential towards mesodermal and endodermal lineages.

Although CF is a clinically heterogeneous disease caused by a defect in the CFTR gene affecting multiple organ systems, major morbidity and mortality are given by the lung disease; however, hepatobiliary complications of CF are increasingly common and clinically relevant as the age of patients increases $[61,62]$. This study shows the differentiative potential of hAMSCs towards hepatocyte-like cells, which might be useful in CF, and highlights the need for further investigations to elucidate the mechanism mediating CFTR expression in hAMSCs upon cell to-cell interactions. 


\section{Conflict of Interests}

The authors declare that they have no conflict of interests.

\section{Acknowledgment}

This study was funded by the Italian Ministry of Health (Ricerca Corrente and Law 548/93).

\section{References}

[1] T. Miki and S. C. Strom, "Amnion-derived pluripotent/multipotent stem cells," Stem Cell Reviews, vol. 2, no. 2, pp. 133$142,2006$.

[2] M. Evangelista, M. Soncini, and O. Parolini, "Placenta-derived stem cells: new hope for cell therapy?” Cytotechnology, vol. 58, no. 1, pp. 33-42, 2008.

[3] O. Parolini, F. Alviano, G. P. Bagnara et al., "Concise review: isolation and characterization of cells from human term placenta: outcome of the first international workshop on placenta derived stem cells," Stem Cells, vol. 26, no. 2, pp. 300-311, 2008.

[4] D. N. Sheppard and M. J. Welsh, "Structure and function of the CFTR chloride channel," Physiological Reviews, vol. 79, no. 1, supplement, pp. S23-S45, 1999.

[5] U. Griesenbach and E. W. F. W. Alton, "Cystic fibrosis gene therapy: successes, failures and hopes for the future," Expert Review of Respiratory Medicine, vol. 3, no. 4, pp. 363-371, 2009.

[6] M. Conese, E. Copreni, D. Piro, and J. Rejman, "Gene and cell therapy for the treatment of cystic fibrosis," Advances in Gene, Molecular and Cell Therapy, vol. 1, pp. 99-119, 2007.

[7] D. Piro, J. Rejman, and M. Conese, "Stem cell therapy for cystic fibrosis: current status and future prospects," Expert Review of Respiratory Medicine, vol. 2, no. 3, pp. 365-380, 2008.

[8] R. Loi, T. Beckett, K. K. Goncz, B. T. Suratt, and D. J. Weiss, "Limited restoration of cystic fibrosis lung epithelium in vivo with adult bone marrow-derived cells," American Journal of Respiratory and Critical Care Medicine, vol. 173, no. 2, pp. 171179, 2006.

[9] E. M. Bruscia, J. E. Price, E.-C. Cheng et al., "Assessment of cystic fibrosis transmembrane conductance regulator (CFTR) activity in CFTR-null mice after bone marrow transplantation," Proceedings of the National Academy of Sciences of the United States of America, vol. 103, no. 8, pp. 2965-2970, 2006.

[10] V. Sueblinvong, R. Loi, P. L. Eisenhauer et al., "Derivation of lung epithelium from human cord blood-derived mesenchymal stem cells," American Journal of Respiratory and Critical Care Medicine, vol. 177, no. 7, pp. 701-711, 2008.

[11] G. Carraro, L. Perin, S. Sedrakyan et al., "Human amniotic fluid stem cells can integrate and differentiate into epithelial lung lineages," Stem Cells, vol. 26, no. 11, pp. 2902-2911, 2008.

[12] T. Miki, F. Marongiu, K. Dorko et al., "Isolation of amniotic mesenchymal stem cells," Current Protocols in Stem Cell Biology, vol. 1, supplement 12, pp. 1E.3.1-E3.10, 2010.

[13] F. Marongiu, R. Gramignoli, Q. Sun et al., "Isolation of amniotic mesenchymal stem cells," Current Protocols in Stem Cell Biology, vol. 1, supplement 12, pp. 1E.5.1-E.5.11, 2010.

[14] L. Porretti, A. Cattaneo, F. Colombo et al., "Simultaneous characterization of progenitor cell compartments in adult human liver," Cytometry A, vol. 77, no. 1, pp. 31-40, 2010.
[15] T. Miki, F. Marongiu, E. C. Ellis et al., "Production of hepatocyte-like cells from human amnion," Methods in Molecular Biology, vol. 481, pp. 155-168, 2009.

[16] K. Anderson, R. Wilkinson, and M. H. Grant, "Assessment of liver function in primary cultures of hepatocytes using diethoxy $(5,6)$ chloromethylfluorescein and confocal laser scanning microscopy," International Journal of Artificial Organs, vol. 21, no. 6, pp. 360-364, 1998.

[17] W. Schormann, F. J. Hammersen, M. Brulport et al., "Tracking of human cells in mice," Histochemistry and Cell Biology, vol. 130, no. 2, pp. 329-338, 2008.

[18] D. Piro, C. Piccoli, L. Guerra et al., "Hematopoietic stem/progenitor cells express functional mitochondrial energy dependent cystic fibrosis transmembrane conductance regulator," Stem Cells and Development. In press.

[19] L. Guerra, T. Fanelli, M. Favia et al., " $\mathrm{Na}^{+} / \mathrm{H}^{+}$exchanger regulatory factor isoform 1 overexpression modulates cystic fibrosis transmembrane conductance regulator (CFTR) expression and activity in human airway 16HBE14o- cells and rescues $\Delta$ F508 CFTR functional expression in cystic fibrosis cells," Journal of Biological Chemistry, vol. 280, no. 49, pp. 4092540933, 2005.

[20] M. F. Pittenger, A. M. Mackay, S. C. Beck et al., "Multilineage potential of adult human mesenchymal stem cells," Science, vol. 284, no. 5411, pp. 143-147, 1999.

[21] K. Le Blanc, F. Frassoni, L. Ball et al., "Mesenchymal stem cells for treatment of steroid-resistant, severe, acute graft-versushost disease: a phase II study," The Lancet, vol. 371, no. 9624, pp. 1579-1586, 2008.

[22] G. D’Ippolito, P. C. Schiller, C. Ricordi, B. A. Roos, and G. A. Howard, "Age-related osteogenic potential of mesenchymal stromal stem cells from human vertebral bone marrow," Journal of Bone and Mineral Research, vol. 14, no. 7, pp. 1115$1122,1999$.

[23] R. J. Scheubel, H. Zorn, R. E. Silber et al., "Age-dependent depression in circulating endothefial progenitor cells in patients undergoing coronary artery bypass grafting," Journal of the American College of Cardiology, vol. 42, no. 12, pp. 2073-2080, 2003.

[24] C. Heeschen, R. Lehmann, J. Honold et al., "Profoundly reduced neovascularization capacity of bone marrow mononuclear cells derived from patients with chronic ischemic heart disease," Circulation, vol. 109, no. 13, pp. 1615-1622, 2004.

[25] P. S. In't Anker, S. A. Scherjon, C. Kleijburg-van der Keur et al., "Isolation of mesenchymal stem cells of fetal or maternal origin from human placenta," Stem Cells, vol. 22, no. 7, pp. 13381345, 2004.

[26] F. Alviano, V. Fossati, C. Marchionni et al., "Term amniotic membrane is a high throughput source for multipotent mesenchymal stem cells with the ability to differentiate into endothelial cells in vitro," BMC Developmental Biology, vol. 7, article 11, 2007.

[27] C. B. Portmann-Lanz, A. Schoeberlein, A. Huber et al., "Placental mesenchymal stem cells as potential autologous graft for pre- and perinatal neuroregeneration," American Journal of Obstetrics and Gynecology, vol. 194, no. 3, pp. 664-673, 2006.

[28] N. Sakuragawa, K. Kakinuma, A. Kikuchi et al., "Human amnion mesenchyme cells express phenotypes of neuroglial progenitor cells," Journal of Neuroscience Research, vol. 78, no. 2, pp. 208-214, 2004.

[29] S. Ilancheran, A. Michalska, G. Peh, E. M. Wallace, M. Pera, and U. Manuelpillai, "Stem cells derived from human fetal membranes display multilineage differentiation potential," Biology of Reproduction, vol. 77, no. 3, pp. 577-588, 2007. 
[30] P. Zhao, H. Ise, M. Hongo, M. Ota, I. Konishi, and T. Nikaido, "Human amniotic mesenchymal cells have some characteristics of cardiomyocytes," Transplantation, vol. 79, no. 5, pp. 528-535, 2005.

[31] C. Ventura, S. Cantoni, F. Bianchi et al., "Hyaluronan mixed esters of butyric and retinoic acid drive cardiac and endothelial fate in term placenta human mesenchymal stem cells and enhance cardiac repair in infarcted rat hearts," Journal of Biological Chemistry, vol. 282, no. 19, pp. 14243-14252, 2007.

[32] J. P. Wei, T. S. Zhang, S. Kawa et al., "Human amnion-isolated cells normalize blood glucose in streptozotocin-induced diabetic mice," Cell Transplantation, vol. 12, no. 5, pp. 545$552,2003$.

[33] R. M. Moore, R. J. Silver, and J. J. Moore, "Physiological apoptotic agents have different effects upon human amnion epithelial and mesenchymal cells," Placenta, vol. 24, no. 2-3, pp. 173 180, 2003.

[34] M. L. Casey and P. C. MacDonald, "Interstitial collagen synthesis and processing in human amnion: a property of the mesenchymal cells," Biology of Reproduction, vol. 55, no. 6, pp. 1253-1260, 1996.

[35] S. Barlow, G. Brooke, K. Chatterjee et al., "Comparison of human placenta- and bone marrow-derived multipotent mesenchymal stem cells," Stem Cells and Development, vol. 17, no. 6, pp. 1095-1107, 2008.

[36] S. Wolbank, A. Peterbauer, M. Fahrner et al., "Dose-dependent immunomodulatory effect of human stem cells from amniotic membrane: a comparison with human mesenchymal stem cells from adipose tissue," Tissue Engineering, vol. 13, no. 6, pp. 1173-1183, 2007.

[37] T. Tamagawa, S. Oi, I. Ishiwata, H. Ishikawa, and Y. Nakamura, "Differentiation of mesenchymal cells derived from human amniotic membranes into hepatocyte-like cells in vitro," $\mathrm{Hu}$ man Cell, vol. 20, no. 3, pp. 77-84, 2007.

[38] G. Bilic, S. M. Zeisberger, A. S. Mallik, R. Zimmermann, and A. H. Zisch, "Comparative characterization of cultured human term amnion epithelial and mesenchymal stromal cells for application in cell therapy," Cell Transplantation, vol. 17, no. 8, pp. 955-968, 2008.

[39] M. Bailo, M. Soncini, E. Vertua et al., "Engraftment potential of human amnion and chorion cells derived from term placenta," Transplantation, vol. 78, no. 10, pp. 1439-1448, 2004.

[40] M. Soncini, E. Vertua, L. Gibelli et al., "Isolation and characterization of mesenchymal cells from human fetal membranes," Journal of Tissue Engineering and Regenerative Medicine, vol. 1, no. 4, pp. 296-305, 2007.

[41] G. Pasquinelli, P. Tazzari, F. Ricci et al., "Ultrastructural characteristics of human mesenchymal stromal (stem) cells derived from bone marrow and term placenta," Ultrastructural Pathology, vol. 31, no. 1, pp. 23-31, 2007.

[42] X. R. Tao, W. L. Li, S. Juan et al., "Clonal mesenchymal stem cells derived from human bone marrow can differentiate into hepatocyte-like cells in injured livers of scid mice," Journal of Cellular Biochemistry, vol. 108, no. 3, pp. 693-704, 2009.

[43] K. Leelawat, S. Narong, S. Chaijan et al., "Proteomic profiles of mesenchymal stem cells induced by a liver differentiation protocol," International Journal of Molecular Sciences, vol. 11, no. 12, pp. 4905-4915, 2010.

[44] S. Kazemnejad, A. Allameh, M. Soleimani et al., "Biochemical and molecular characterization of hepatocyte-like cells derived from human bone marrow mesenchymal stem cells on a novel three-dimensional biocompatible nanofibrous scaffold," Journal of Gastroenterology and Hepatology, vol. 24, no. 2, pp. 278 287, 2009
[45] J. K. Henderson, J. S. Draper, H. S. Baillie et al., "Preimplantation human embryos and embryonic stem cells show comparable expression of stage-specific embryonic antigens," Stem Cells, vol. 20, no. 4, pp. 329-337, 2002.

[46] E. J. Gang, D. Bosnakovski, C. A. Figueiredo, J. W. Visser, and R. C. Perlingeiro, "SSEA-4 identifies mesenchymal stem cells from bone marrow," Blood, vol. 109, no. 4, pp. 1743-1751, 2007.

[47] E. Pierantozzi, B. Gava, I. Manini et al., "Pluripotency regulators in human mesenchymal stem cells: expression of NANOG but not of OCT-4 and SOX-2," Stem Cells and Development, vol. 20, no. 5, pp. 915-923, 2011.

[48] D. J. Weiss, M. A. Berberich, Z. Borok et al., "Adult stem cells, lung biology, and lung disease. NHLBI/Cystic fibrosis foundation workshop," Proceedings of the American Thoracic Society, vol. 3, no. 3, pp. 193-207, 2006.

[49] G. Wang, B. A. Bunnell, R. G. Painter et al., "Adult stem cells from bone marrow stroma differentiate into airway epithelial cells: potential therapy for cystic fibrosis," Proceedings of the National Academy of Sciences of the United States of America, vol. 102, no. 1, pp. 186-191, 2005.

[50] A. Erices, P. Conget, and J. J. Minguell, "Mesenchymal progenitor cells in human umbilical cord blood," British Journal of Haematology, vol. 109, no. 1, pp. 235-242, 2000.

[51] K. Mareschi, E. Biasin, W. Piacibello, M. Aglietta, E. Madon, and F. Fagioli, "Isolation of human mesenchymal stem cells: bone marrow versus umbilical cord blood," Haematologica, vol. 86, no. 10, pp. 1099-1100, 2001.

[52] S. A. Wexler, C. Donaldson, P. Denning-Kendall, C. Rice, B. Bradley, and J. M. Hows, "Adult bone marrow is a rich source of human mesenchymal "stem" cells but umbilical cord and mobilized adult blood are not," British Journal of Haematology, vol. 121, no. 2, pp. 368-374, 2003.

[53] A. Ben-Chetrit, M. Antenos, A. Jurisicova et al., "Expression of cystic fibrosis transmembrane conductance regulator during early human embryo development," Molecular Human Reproduction, vol. 8, no. 8, pp. 758-764, 2002.

[54] X. T. Mo, S. C. Guo, H. Q. Xie et al., "Variations in the ratios of co-cultured mesenchymal stem cells and chondrocytes regulate the expression of cartilaginous and osseous phenotype in alginate constructs," Bone, vol. 45, no. 1, pp. 42-51, 2009.

[55] L. Bian, D. Y. Zhai, R. L. Mauck, and J. A. Burdick, "Coculture of human mesenchymal stem cells and articular chondrocytes reduces hypertrophy and enhances functional properties of engineered cartilage," Tissue Engineering A, vol. 17, no. 7-8, pp. 1137-1145, 2011.

[56] Y. Maeda, V. Dave, and J. A. Whitsett, "Transcriptional control of lung morphogenesis," Physiological Reviews, vol. 87, no. 1, pp. 219-244, 2007.

[57] L. Badri, N. M. Walker, T. Ohtsuka et al., "Epithelial interactions and local engraftment of lung-resident mesenchymal stem cells," American Journal of Respiratory Cell and Molecular Biology, vol. 45, no. 4, pp. 809-816, 2011.

[58] T. S. Jiang, L. Cai, W. Y. Ji et al., "Reconstruction of the corneal epithelium with induced marrow mesenchymal stem cells in rats," Molecular Vision, vol. 16, pp. 1304-1316, 2010.

[59] J. Xu, X. Liu, J. Chen et al., "Cell-cell interaction promotes rat marrow stromal cell differentiation into endothelial cell via activation of TACE/TNF- $\alpha$ signaling," Cell Transplantation, vol. 19, no. 1, pp. 43-53, 2010.

[60] S. L. Farmen, P. H. Karp, P. Ng et al., "Gene transfer of CFTR to airway epithelia: low levels of expression are sufficient to correct $\mathrm{Cl}$ - transport and overexpression can generate basolateral CFTR," American Journal of Physiology, vol. 289, no. 6, pp. L1123-L1130, 2005. 
[61] C. Colombo, "Liver disease in cystic fibrosis," Current Opinion in Pulmonary Medicine, vol. 13, no. 6, pp. 529-536, 2007.

[62] K. Moyer and W. Balistreri, "Hepatobiliary disease in patients with cystic fibrosis," Current Opinion in Gastroenterology, vol. 25, no. 3, pp. 272-278, 2009. 

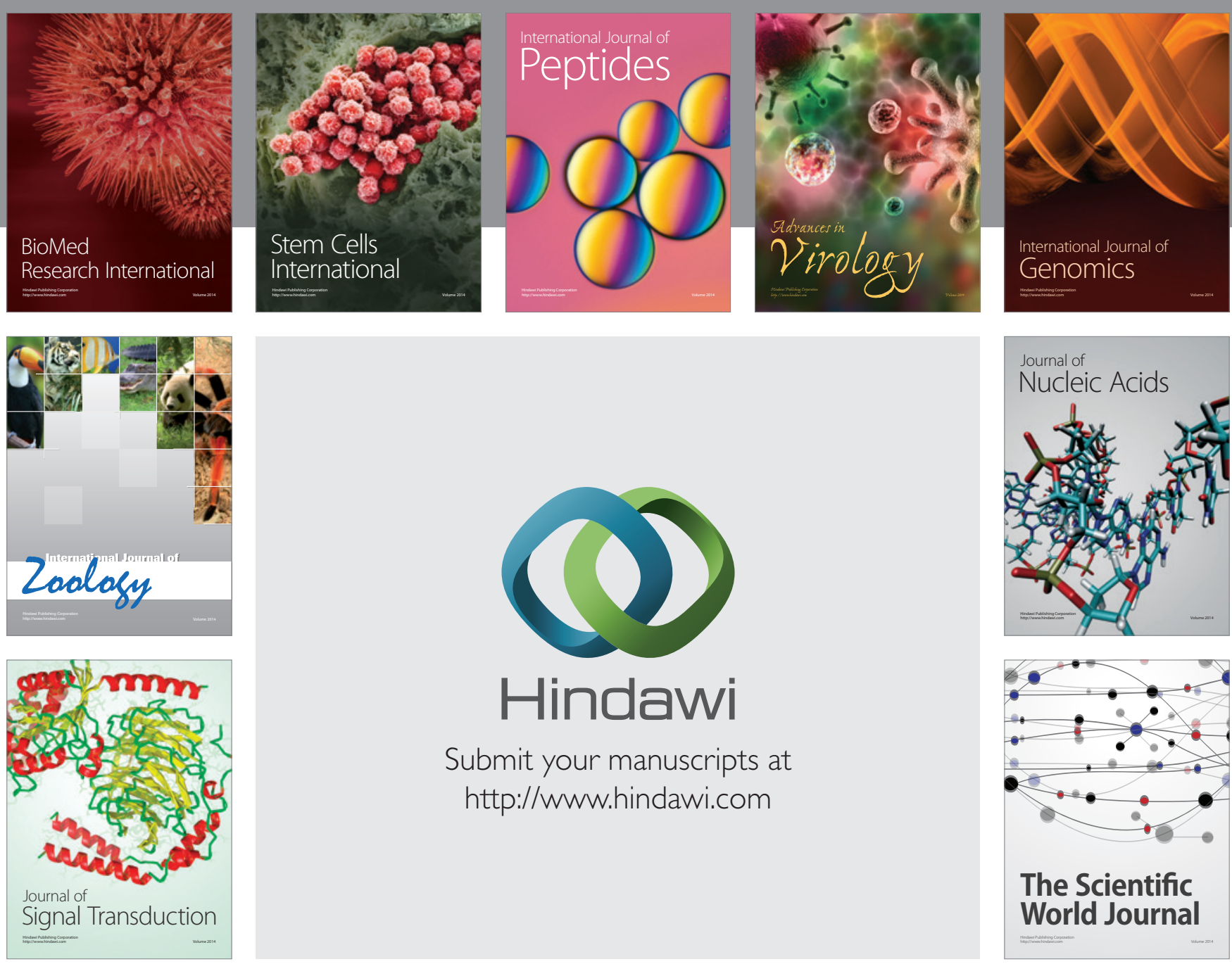

Submit your manuscripts at

http://www.hindawi.com
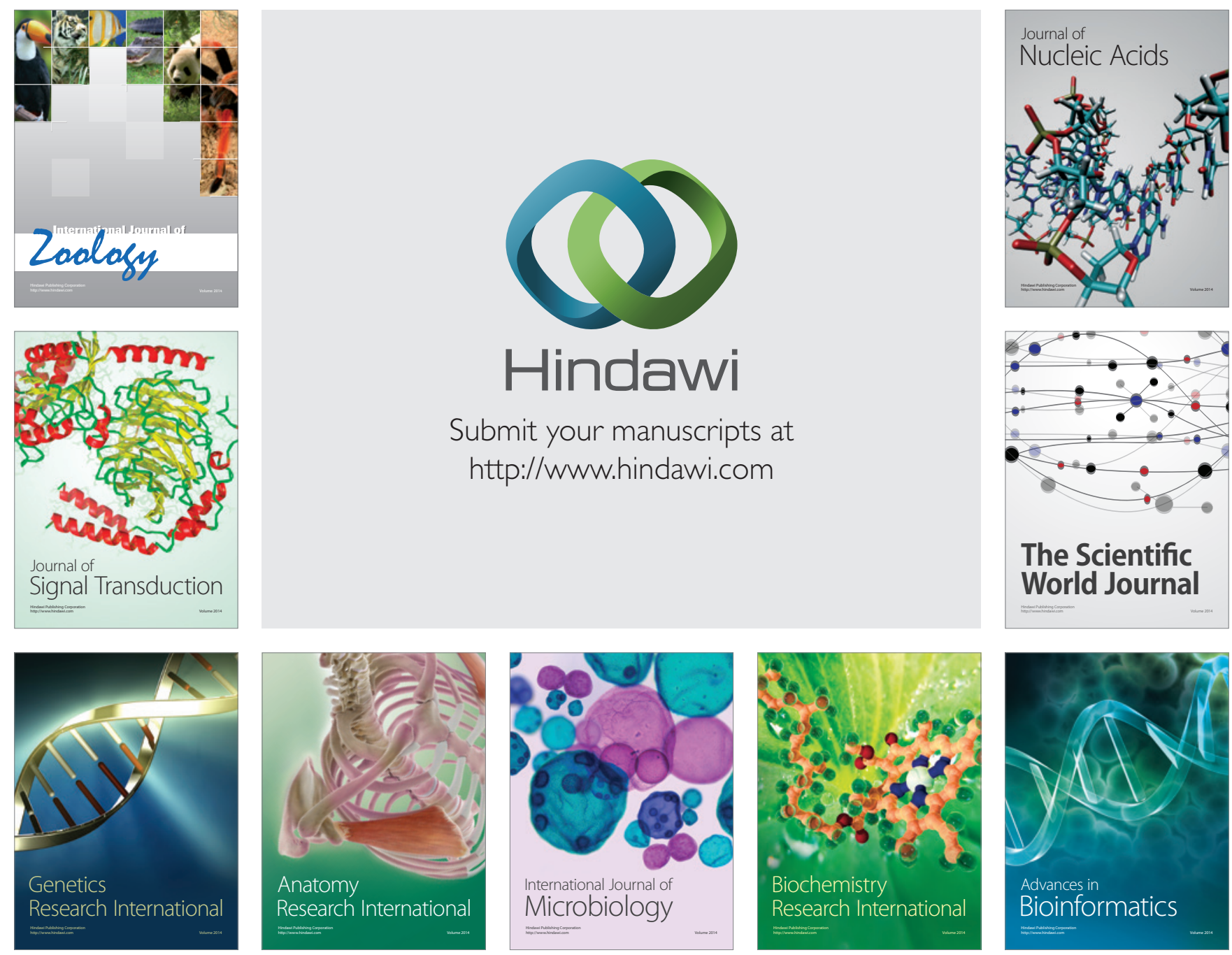

The Scientific World Journal
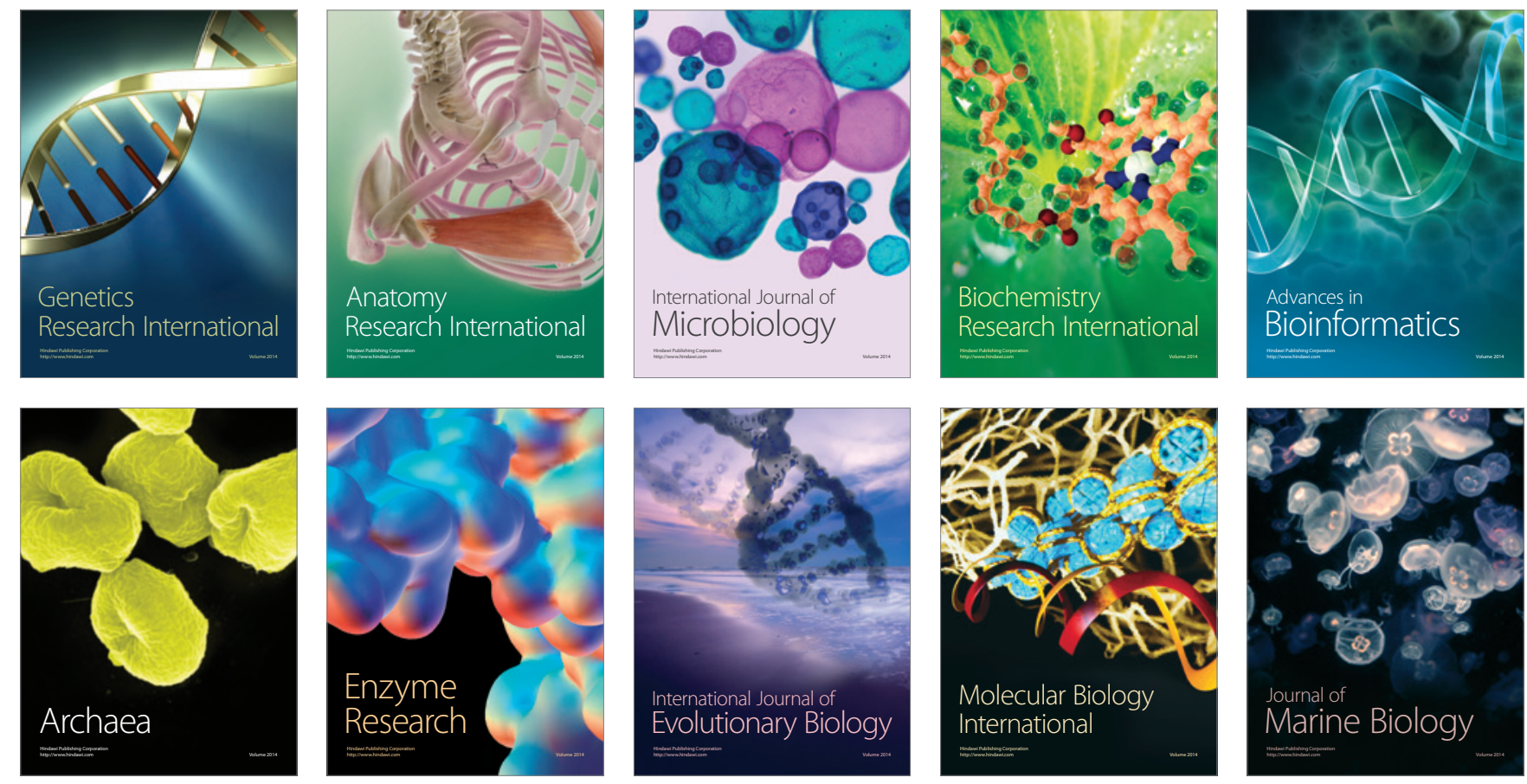